\title{
Genomic and Phenotypic Analysis of COVID-19-Associated Pulmonary Aspergillosis Isolates of Aspergillus fumigatus
}

\author{
(D) Jacob L. Steenwyk, ${ }^{a}$ (D) Matthew E. Mead, ${ }^{a}$ Patrícia Alves de Castro, ${ }^{b}$ Clara Valero, ${ }^{b}$ André Damasio, ${ }^{c, d}$ Renato A. C. dos Santos, ${ }^{b}$

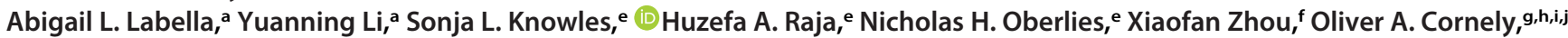 \\ (D)Frieder Fuchs, ${ }^{k}$ Philipp Koehler,g,h (D) Gustavo H. Goldman, ${ }^{b}$ (D) Antonis Rokas ${ }^{a}$

\begin{abstract}
aDepartment of Biological Sciences, Vanderbilt University, Nashville, Tennessee, USA
bFaculdade de Ciências Farmacêuticas de Ribeirão Preto, Universidade de São Paulo, Ribeirão Preto, Brazil

Institute of Biology, University of Campinas (UNICAMP), Campinas-SP, Brazil

dExperimental Medicine Research Cluster (EMRC), University of Campinas (UNICAMP), Campinas-SP, Brazil

eDepartment of Chemistry and Biochemistry, University of North Carolina at Greensboro, Greensboro, North Carolina, USA

fGuangdong Laboratory for Lingnan Modern Agriculture, Guangdong Province Key Laboratory of Microbial Signals and Disease Control, Integrative Microbiology Research Centre, South China Agricultural University, Guangzhou, China

gUniversity of Cologne, Medical Faculty and University Hospital Cologne, Department I of Internal Medicine, Excellence Center for Medical Mycology (ECMM), Cologne, Germany

nUniversity of Cologne, Cologne Excellence Cluster on Cellular Stress Responses in Aging-Associated Diseases (CECAD), Cologne, Germany

iZKS Köln, Clinical Trials Centre Cologne, Cologne, Germany

JGerman Center for Infection Research (DZIF), Partner Site Bonn-Cologne, Medical Faculty and University Hospital Cologne, University of Cologne, Cologne, Germany

kFaculty of Medicine, Institute for Medical Microbiology, Immunology and Hygiene, University of Cologne, Cologne, Germany
\end{abstract}

ABSTRACT The ongoing global pandemic caused by the severe acute respiratory syndrome coronavirus 2 (SARS-CoV-2) is responsible for coronavirus disease 2019 (COVID-19), first described in Wuhan, China. A subset of COVID-19 patients has been reported to have acquired secondary infections by microbial pathogens, such as opportunistic fungal pathogens from the genus Aspergillus. To gain insight into COVID-19-associated pulmonary aspergillosis (CAPA), we analyzed the genomes and characterized the phenotypic profiles of four CAPA isolates of Aspergillus fumigatus obtained from patients treated in the area of North Rhine-Westphalia, Germany. By examining the mutational spectrum of single nucleotide polymorphisms, insertiondeletion polymorphisms, and copy number variants among 206 genes known to modulate $A$. fumigatus virulence, we found that CAPA isolate genomes do not exhibit significant differences from the genome of the Af293 reference strain. By examining a number of factors, including virulence in an invertebrate moth model, growth in the presence of osmotic, cell wall, and oxidative stressors, secondary metabolite biosynthesis, and the MIC of antifungal drugs, we found that CAPA isolates were generally, but not always, similar to A. fumigatus reference strains Af293 and CEA17. Notably, CAPA isolate D had more putative loss-of-function mutations in genes known to increase virulence when deleted. Moreover, CAPA isolate D was significantly more virulent than the other three CAPA isolates and the $A$. fumigatus reference strains Af293 and CEA17, but similarly virulent to two other clinical strains of A. fumigatus. These findings expand our understanding of the genomic and phenotypic characteristics of isolates that cause CAPA.

IMPORTANCE The global pandemic caused by severe acute respiratory syndrome coronavirus 2 (SARS-CoV-2), the etiological agent of coronavirus disease 2019 (COVID19), has already killed millions of people. COVID-19 patient outcome can be further complicated by secondary infections, such as COVID-19-associated pulmonary aspergillosis (CAPA). CAPA is caused by Aspergillus fungal pathogens, but there is little information about the genomic and phenotypic characteristics of CAPA isolates. We
Citation Steenwyk JL, Mead ME, de Castro PA Valero C, Damasio A, dos Santos RAC, Labella AL, Li Y, Knowles SL, Raja HA, Oberlies NH, Zhou X, Cornely OA, Fuchs F, Koehler P, Goldman GH, Rokas A. 2021. Genomic and phenotypic analysis of COVID-19-associated pulmonary aspergillosis isolates of Aspergillus fumigatus. Microbiol Spectr 9:e00010-21. https://doi.org/ 10.1128/Spectrum.00010-21

Editor Christina A. Cuomo, Broad Institute

Copyright $\odot 2021$ Steenwyk et al. This is an open-access article distributed under the terms of the Creative Commons Attribution 4.0 International license.

Address correspondence to Philipp Koehler, philipp.koehler@uk-koeln.de, Gustavo H. Goldman, ggoldman@usp.br, or Antonis Rokas, antonis.rokas@vanderbilt.edu.

3 Characterization of genomic and phenotypic heterogeneity of COVID-19associated pulmonary aspergillosis (CAPA) isolates of Aspergillus fumigatus. @jlsteenwyk, @OberliesGroup, @KoehlerPh, @FungalSao, @RokasLab

Received 8 April 2021

Accepted 8 April 2021

Published 9 June 2021 
conducted genome sequencing and extensive phenotyping of four CAPA isolates of Aspergillus fumigatus from Germany. We found that CAPA isolates were often, but not always, similar to other reference strains of $A$. fumigatus across 206 genetic determinants of infection-relevant phenotypes, including virulence. For example, CAPA isolate D was more virulent than other CAPA isolates and reference strains in an invertebrate model of fungal disease, but similarly virulent to two other clinical strains. These results expand our understanding of COVID-19-associated pulmonary aspergillosis.

KEYWORDS pathogenicity, coinfection, secondary infection, virulence factors, superinfection, acute respiratory distress syndrome, Aspergillus, aspergillosis, COVID-19

n 11 March 2020, the World Health Organization declared the ongoing pandemic caused by SARS-CoV-2, which causes COVID-19, a global emergency (1). Similar to other viral infections, patients may be more susceptible to microbial secondary infections, which can complicate disease management strategies and result in adverse patient outcomes $(2,3)$. For example, approximately one quarter of patients infected with the H1N1 influenza virus during the 2009 pandemic were also infected with bacteria or fungi $(4,5)$. Among COVID-19 patients, one study found that $\sim 17 \%$ of individuals also have bacterial infections (6) and another that $\sim 40 \%$ of patients with severe COVID-19 pneumonia were also infected with filamentous fungi from the genus Aspergillus (7). A third study reported that $\sim 26 \%$ of patients with acute respiratory distress syndrome-associated COVID-19 were also infected with Aspergillus fumigatus and had high rates of mortality (8). Other studies from around the world have also reported high incidences of Aspergillus infections among patients with COVID-19 (9-12). Taken together, these findings have prompted some to suggest routine clinical testing for secondary infections of Aspergillus fungi among COVID-19 patients (13, 14). Despite the prevalence of microbial infections and their association with adverse patient outcomes, these secondary infections are only beginning to be understood.

Invasive pulmonary aspergillosis is caused by tissue infiltration of Aspergillus species after inhalation of their asexual spores (Fig. 1); more than 250,000 aspergillosis infections are estimated to occur annually and have high mortality rates (15). The major etiological agent of aspergillosis is A. fumigatus (16), although a few other Aspergillus species are also known to cause aspergillosis (17-20). Numerous factors are known to be associated with $A$. fumigatus pathogenicity, including its ability to grow at the human body temperature $\left(37^{\circ} \mathrm{C}\right)$ and withstand oxidative stress (21-32). Disease management of $A$. fumigatus is further complicated by resistance to antifungal drugs among strains (33-36) and $A$. fumigatus strains have been shown to exhibit strain heterogeneity with respect to virulence and pathogenicity-associated traits $(18,32,37-40)$. However, it remains unclear whether the genomic and pathogenicity-related phenotypic characteristics of CAPA isolates are similar to or distinct from those of previously studied clinical strains of $A$. fumigatus.

To address this question and gain insight into the pathobiology of $A$. fumigatus CAPA isolates, we examined the genomic and phenotypic characteristics of four CAPA isolates obtained from four critically ill patients of two different centers in Cologne, Germany (8) (Table 1). All patients were submitted to intensive care units due to moderate to severe respiratory distress syndrome (ARDS). Genome-scale phylogenetic (or phylogenomic) analyses revealed CAPA isolates formed a monophyletic group closely related to reference strains Af293 and A1163. Examination of the mutational spectra of 206 genes known to modulate virulence in A. fumigatus (which are here referred to as genetic determinants of virulence) revealed several putative loss-of-function (LOF) mutations. Notably, CAPA isolate D had the most putative LOF mutations among genes whose null mutants are known to increase virulence. The profiles of pathogenicity-related traits and of secondary metabolites of the CAPA isolates were similar to those of reference $A$. fumigatus strains Af293 and CEA17 or CEA10, which are parental 


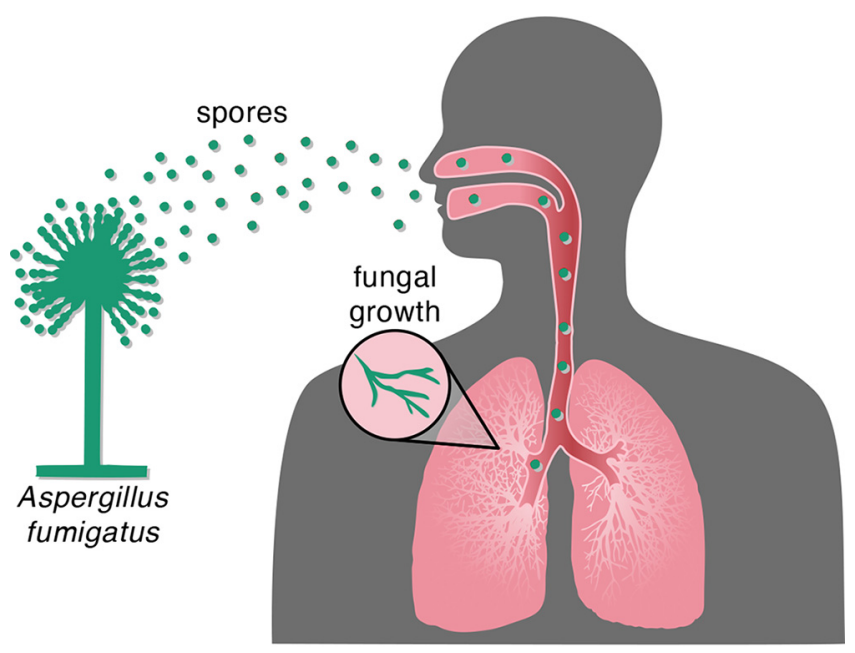

FIG 1 Inhalation of Aspergillus spores can result in fungal infection. Inhalation of Aspergillus spores from the environment can travel to the lung and then grow vegetatively and spread to other parts of the body.

strains of A1163 (41). One notable exception was that CAPA isolate D was significantly more virulent than other strains in an invertebrate model of disease, but on par with two other clinical strains of $A$. fumigatus. These results suggest that the genomes of $A$. fumigatus CAPA isolates contain nearly complete and intact repertoires of genetic determinants of virulence and have phenotypic profiles that are broadly expected for A. fumigatus clinical isolates. However, we did find evidence for genetic and phenotypic strain heterogeneity. These results suggest the CAPA isolates show similar phenotypic profiles as A. fumigatus clinical strains Af293 and A1163 and expand our understanding of CAPA.

\section{RESULTS AND DISCUSSION}

CAPA isolates belong to $A$. fumigatus and are closely related to reference strains Af293 and A1163. To confirm that the CAPA isolates belong to A. fumigatus, we sequenced, assembled, and annotated their genomes (Table S1 in the supplemental material; see figshare, 10.6084/m9.figshare.13118549). Phylogenetic analyses conducted using tef1 (Fig. S1) and calmodulin (Fig. S2) sequences suggested that all CAPA isolates are A. fumigatus. Phylogenomic analysis using 50 Aspergillus genomes (the four CAPA isolates, $43 \mathrm{~A}$. fumigatus genomes that span the known diversity of the species,

TABLE 1 Metainformation and NCBI accessions for CAPA isolates

\begin{tabular}{|c|c|c|c|c|c|c|c|c|c|}
\hline Isolate $^{a}$ & $\begin{array}{l}\text { Patient } \\
\text { identifier }\end{array}$ & $\begin{array}{l}\text { Patient } \\
\text { outcome }\end{array}$ & $\begin{array}{l}\text { Patient } \\
\text { age }\end{array}$ & $\begin{array}{l}\text { Patient } \\
\text { sex }\end{array}$ & $\begin{array}{l}\text { Patient } \\
\text { immunocompromising } \\
\text { condition }\end{array}$ & $\begin{array}{l}\text { Biological source } \\
\text { of fungal isolate }\end{array}$ & $\begin{array}{l}\text { Antifungal } \\
\text { treatment }^{c}\end{array}$ & Antiviral treatment ${ }^{b}$ & $\begin{array}{l}\text { NCBI BioSample/ } \\
\text { sequence read } \\
\text { archive accessions }\end{array}$ \\
\hline$\overline{\text { CAPA A }}$ & $\begin{array}{r}\text { Patient from } \\
\text { this study }\end{array}$ & Deceased & 57 & Male & None & Bronchial aspirate & $\begin{array}{l}\text { Caspofungin (70/ } \\
50 \mathrm{mg} \text { once daily) }\end{array}$ & Supportive only & $\begin{array}{l}\text { SAMN16591136; } \\
\text { SRR12949929 }\end{array}$ \\
\hline CAPA B & Patient no. 4 & Deceased & 73 & Male & $\begin{array}{l}\text { Inhalational steroids for } \\
\text { medical history of } \\
\text { chronic obstructive } \\
\text { pulmonary disease }\end{array}$ & Bronchial aspirate & $\begin{array}{l}\text { Voriconazole i.v. } \\
\text { (6/4 mg/kg BW } \\
\text { twice daily) }\end{array}$ & Supportive only & $\begin{array}{r}\text { SAMN16591179; } \\
\text { SRR12949928 }\end{array}$ \\
\hline CAPAC & Patient no. 3 & Alive & 54 & Male & $\begin{array}{l}\text { IV corticosteroid } \\
\text { therapy } 0.4 \mathrm{mg} / \mathrm{kg} / \\
\text { day, total of } 13 \text { days }\end{array}$ & $\begin{array}{l}\text { Bronchoalveolar } \\
\text { lavage fluid }\end{array}$ & $\begin{array}{l}\text { Caspofungin ( } 70 / \\
50 \mathrm{mg} \text { once daily) } \\
\text { followed by i.v. } \\
\text { voriconazole } \\
(6 / 4 \mathrm{mg} / \mathrm{kg} \mathrm{BW} \\
\text { twice daily) }\end{array}$ & $\begin{array}{l}\text { Hydroxychloroquine, } \\
\text { darunavir and cobicistat } \\
\text { at external hospital, in } \\
\text { house changed to } \\
\text { supportive only }\end{array}$ & $\begin{array}{r}\text { SAMN16591190; } \\
\text { SRR12949927 }\end{array}$ \\
\hline CAPA D & Patient no.1 & Deceased & 62 & Female & $\begin{array}{l}\text { Inhalational steroids for } \\
\text { medical history of } \\
\text { chronic obstructive } \\
\text { pulmonary disease }\end{array}$ & $\begin{array}{l}\text { Bronchoalveolar } \\
\text { lavage fluid }\end{array}$ & $\begin{array}{l}\text { Voriconazole i.v. } \\
\text { (6/4 mg/kg BW } \\
\text { twice daily) }\end{array}$ & Supportive only & $\begin{array}{r}\text { SAMN16591200; } \\
\text { SRR12949926 }\end{array}$ \\
\hline
\end{tabular}

anformation on CAPA isolates B, C, and D is from reference 8 , where the isolates were first described. CAPA isolate A is being reported for the first time. ${ }^{b}$ Supportive only antiviral treatment indicates no specific antiviral treatment was given.

'BW, body weight; i.v., intravenous; $\mathrm{kg}$, kilogram; mg, milligram. 
including strains Af293 and A1163 (18, 29, 42-47), Aspergillus fischeri strains NRRL 181 and NRRL 4585, and Aspergillus oerlinghausenensis strain CBS 139183') $(40,45)$ confirmed that all CAPA isolates are A. fumigatus (Fig. 2). Phylogenomic analyses also revealed the CAPA isolates formed a monophyletic group closely related to reference strains Af293 and A1163. CAPA isolates are inferred to be closely related, which may be due to the fact they are all from the same geographic area.

CAPA isolate genomes contain polymorphisms in genetic determinants of virulence and biosynthetic gene clusters. An extensive literature and database search identified 206 genetic determinants of virulence (File S1) (23, 48-51). We define genetic determinants of virulence as genes that alter virulence in an animal model of disease when deleted or that are required for biosynthesis of secondary metabolites known to affect virulence. This definition resulted in a list of genes distinct from those previously published, which include genes that contribute to allergy-related phenotypes and genes that are computationally predicted to contribute to virulence but have yet to be validated in an animal model of fungal disease (52-55).

To determine if the 206 genetic determinants of virulence are conserved in CAPA isolates, we conducted sequence similarity searches of gene sequences in the genomes of the CAPA isolates. We found that all 206 genes were present in the genomes of the CAPA isolates. Furthermore, none of the 206 genetic determinants of virulence showed any copy number variation among CAPA isolates. Examination of single nucleotide polymorphisms (SNPs) and insertion/deletion (indel) polymorphisms coupled with variant effect prediction in these 206 genes (Fig. 3; File S2) showed that all CAPA isolates shared multiple polymorphisms resulting in early stop codons or frameshift mutations suggestive of loss of function (LOF) in NRPS8 (AFUA_5G12730), a nonribosomal peptide synthetase gene that encodes an unknown secondary metabolite (42). LOF mutations in NRPS8 are known to result in increased virulence in a mouse model of disease (56). Putative LOF mutations were also observed in genes whose null mutants decreased virulence. For example, all CAPA isolates shared the same SNPs resulting in early stop codons that likely result in LOF or partial LOF in pptA (AFUA_2G08590), a putative 4'-phosphopantetheinyl transferase, whose deletion results in reduced virulence in a mouse model of disease (57). In light of the close evolutionary relationships among CAPA isolates, we hypothesize that these shared mutations likely occurred in the genome of their most recent common ancestor.

In addition to shared polymorphisms, analyses of CAPA isolate genomes also revealed isolate-specific polymorphisms affecting genetic determinants of virulence (File S2). For example, SNPs resulting in early stop codons, which likely lead to LOF, were observed in CYP5081A1 (AFUA_4G14780), a putative cytochrome P450 monooxygenase, in CAPA isolates $B$ and C. CYP5081A1 LOF is associated with reduced virulence of $A$. fumigatus (58). Other SNPs were found only in single isolates. CAPA isolate $B$ has a frameshift mutation in a putative fatty acid oxygenase (AFUA_4G00180). CAPA isolate $D$ has a mutation resulting in the loss of the start codon in fleA (AFUA_5G14740), a gene that encodes an L-fucose-specific lectin. Mice infected with FLEA null mutants have more severe pneumonia and invasive aspergillosis than wild-type strains. FLEA null mutants cause more severe disease because FleA binds to macrophages and therefore is critical for host recognition, clearance, and macrophage killing (59). The only evidence of pseudogenization among the genetic determinants of virulence in the reference strains was observed in mybA (AFUA_3G07070), a transcription factor involved in conidiation and conidial viability (60), in strain A1163. MybA null mutants have reduced virulence compared to wild-type strains (60).

Examination of three additional clinical strains of A. fumigatus (IFM61407, CNCM7555, and Afs35) revealed that CAPA isolates shared some, but not all, polymorphisms present in the 206 genetic determinants of virulence. For example, similar putative LOF mutations were observed in NRPS8 (AFUA_5G12730). Polymorphisms that were not shared between CAPA isolates and the three clinical strains include the loss of a stop codon in aspA, a septin (61), in strain Afs35; an early stop codon in noc3, a nuclear export protein (62), in strain CN-CM7555; and a lost stop codon in cat2, a 


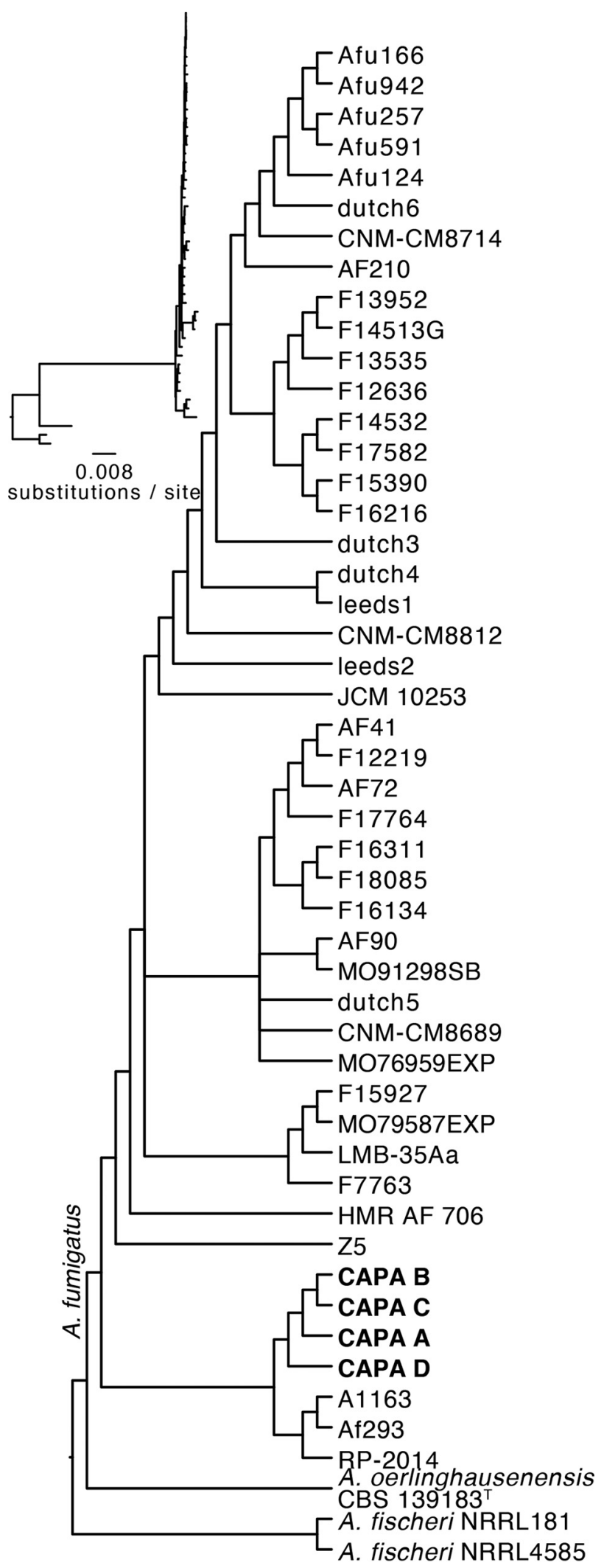

FIG 2 Phylogenomics confirms that COVID-19-associated pulmonary aspergillosis (CAPA) isolates are Aspergillus fumigatus. Phylogenomic analysis of a concatenated matrix of 4,525 single-copy orthologous groups genes (sites: 7,133,367) confirmed CAPA isolates are A. fumigatus. Furthermore, CAPA isolates are closely related to reference strains A1163 and Af293. Bipartitions with less than $85 \%$ ultrafast bootstrap approximation support were collapsed. 


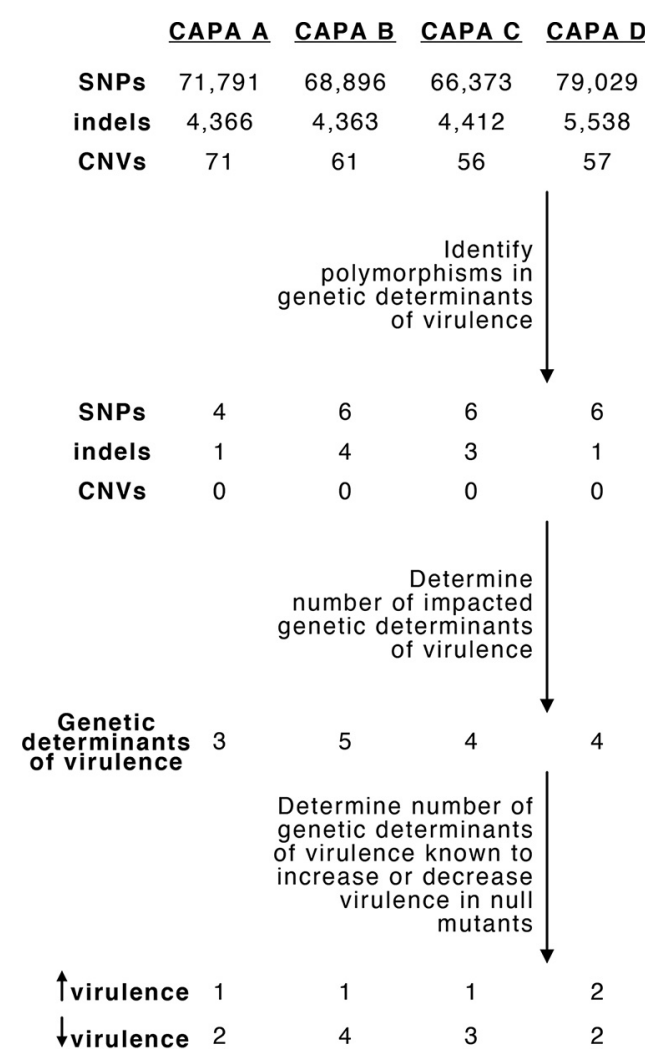

FIG 3 Mutational spectra among genetic determinants of virulence. Genome-wide SNPs, indels, and $\mathrm{CN}$ variants were filtered for those present in genetic determinants of virulence. Then, the number of genetic determinants of virulence with high-impact polymorphisms was identified. The number known to increase or decrease virulence in null mutants was determined thereafter.

bifunctional catalase-peroxidase (63), in strain IFM61407. A complete list of highimpact polymorphisms in the three clinical strains is available in File S2.

Examination of the presence of biosynthetic gene clusters (BGCs) revealed that all CAPA isolates had BGCs that encode secondary metabolites known to modulate host biology (Table 2). For example, all CAPA isolates had BGCs encoding the toxic secondary metabolite gliotoxin (Fig. 4). Other intact BGCs in the genomes of the CAPA isolates include fumitremorgin, trypacidin, pseurotin, and fumagillin, which are known to modulate host biology (64-66); for example, fumagillin is known to inhibit neutrophil function $(67,68)$. More broadly, all CAPA isolates had similar numbers and classes of BGCs (Fig. S3).

In summary, we found that CAPA isolates were closely related to one another and had largely intact genetic determinants of virulence and BGCs. However, we observed

TABLE 2 Biosynthetic gene clusters that produce secondary metabolites implicated in modulating host biology in A. fumigatus

\begin{tabular}{|c|c|c|c|c|c|c|}
\hline \multirow[b]{2}{*}{ Metabolite } & \multirow[b]{2}{*}{ Function } & \multirow[b]{2}{*}{ Reference(s) } & \multicolumn{4}{|c|}{$\begin{array}{l}\text { Evidence of biosynthetic gene cluster/secondary } \\
\text { metabolite }^{a}\end{array}$} \\
\hline & & & CAPA A & CAPA B & CAPAC & CAPA D \\
\hline Gliotoxin & Inhibits host immune response & 72 & $+/+$ & $+/+$ & $+/+$ & $+/+$ \\
\hline Fumitremorgin & Inhibits the breast cancer resistance protein & 64 & $+/+$ & $+/+$ & $+/+$ & $+/+$ \\
\hline Trypacidin & Damages lung cell tissues & 65 & $+/-$ & $+/-$ & $+1-$ & $+/-$ \\
\hline Pseurotin & Inhibits immunoglobulin E & 66 & $+/+$ & $+/+$ & $+/+$ & $+/-$ \\
\hline Fumagillin & Inhibits neutrophil function & 67,68 & $+/+$ & $+/+$ & $+/+$ & $+/+$ \\
\hline
\end{tabular}

\footnotetext{
aThe symbols + and - indicate the presence and absence of a BGC and secondary metabolite, respectively. For example, $+/-$ indicates the presence of the BGC but no evidence of secondary metabolite production. Evidence of robust secondary metabolite production is defined as evidence of the secondary metabolite across all three replicates. (See Fig. S6 in the supplemental material for relative abundance of secondary metabolite production.)
} 


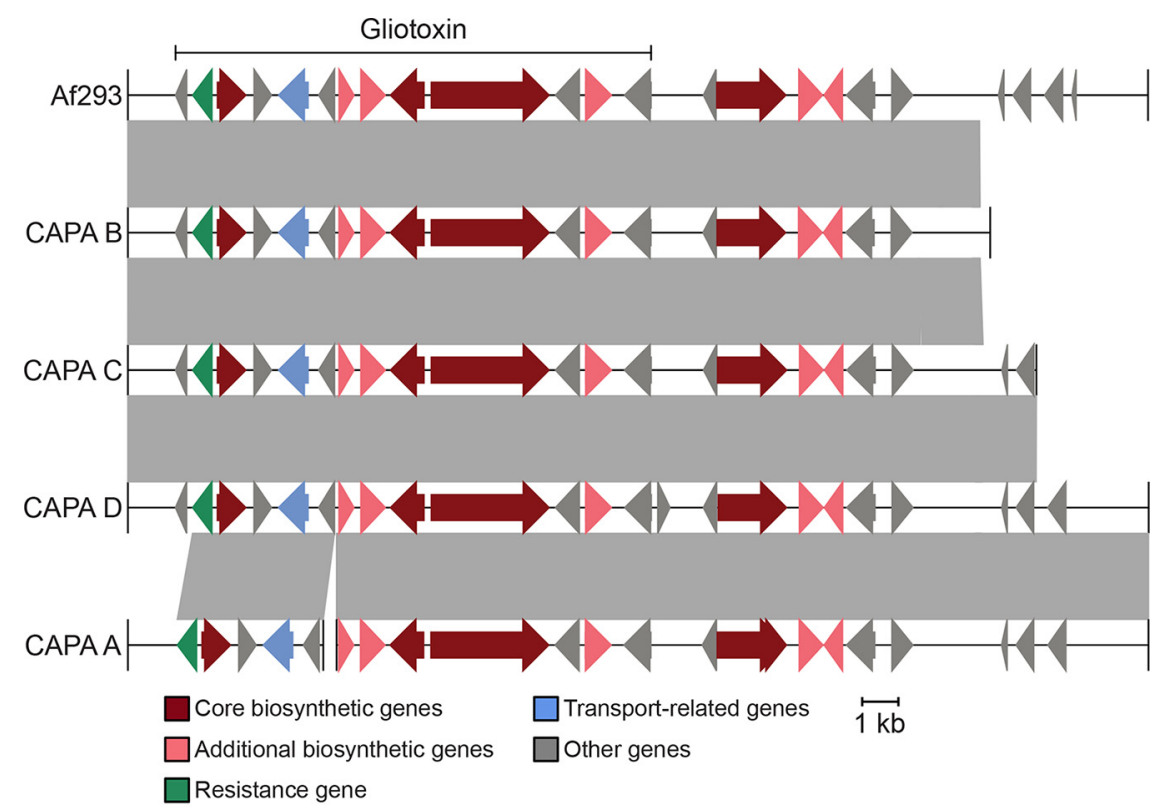

FIG 4 COVID-19-associated pulmonary aspergillosis (CAPA) isolates of Aspergillus fumigatus have biosynthetic gene clusters (BGCs) that encode the toxic small molecule gliotoxin. Gliotoxin is known to contribute to virulence of $A$. fumigatus. The genomes of CAPA isolates of $A$. fumigatus contain biosynthetic gene clusters known to encode gliotoxin. Note, the BGC of CAPA isolate A was split between two contigs and, therefore, the BGC is hypothesized to be present.

strain-specific polymorphisms in known genetic determinants of virulence in CAPA isolate genomes, which raises the hypothesis that CAPA isolates differ in their virulence profiles.

CAPA isolates display strain heterogeneity in virulence and in a few virulencerelated traits. Examination of virulence and virulence-related traits revealed the CAPA isolates often, but not always, had similar phenotypic profiles compared to reference A. fumigatus strains Af293 and a CEA17 $\Delta a k u B^{\mathrm{KU} 80} \mathrm{pyrG}^{+}$derivative of CEA17 $a k u B^{\mathrm{KU} 80+}{ }^{\text {, }} \mathrm{pyrG}^{-}$(which is here referred to as CEA17 for simplicity [41]). For example, virulence in the Galleria moth model of fungal disease revealed strain heterogeneity among CAPA isolates Af293, CEA17, and a panel of three clinical strains of $A$. fumigatus, namely, Afs35, IFM61407, and CN-CM7555 $(41,69,70)(P<0.001$; log-rank test; Fig. 5A). Pairwise examination revealed the observed strain heterogeneity was primarily driven by CAPA isolate D, which was significantly more virulent than all other CAPA isolates, reference strains Af293 and CEA17, and clinical strain Afs35 (Benjamini-Hochberg adjusted $P$ value $<0.05$ when comparing CAPA isolate $D$ to another isolate; log-rank test; File S3). However, the virulence of the CAPA isolate D was on par to those of clinical strains IFM61407 and CN-CM 7555 ( $P=0.085$ and $P=0.386$, respectively) (Fig. 5A). These results reveal the CAPA isolates have generally similar virulence profiles compared to the reference strains Af293 and CEA17 with the exception of the more virulent CAPA isolate D. Furthermore, the virulence profiles of all CAPA isolates are within the known range of $A$. fumigatus clinical strains. Determining the association between virulence and the genetic polymorphisms described in the section above, in addition to other polymorphisms identified in this study (Fig. 3), is an important future direction.

Examination of growth in the presence of osmotic, cell wall, and oxidative stressors revealed the phenotypic profiles of CAPA isolates were similar to the profiles of Af293 and CEA17 strains (Fig. 5B to D and Fig. S4). The sole exception was growth in the presence of calcofluor white, where we observed that the CAPA isolates were more sensitive than reference strains Af293 and CEA17 ( $P<0.001$; Tukey's honestly significant difference test; Fig. 5C). Last, antifungal drug susceptibility profiles for amphotericin $B$, voriconazole, itraconazole, and posaconazole were similar between the CAPA isolates 
A

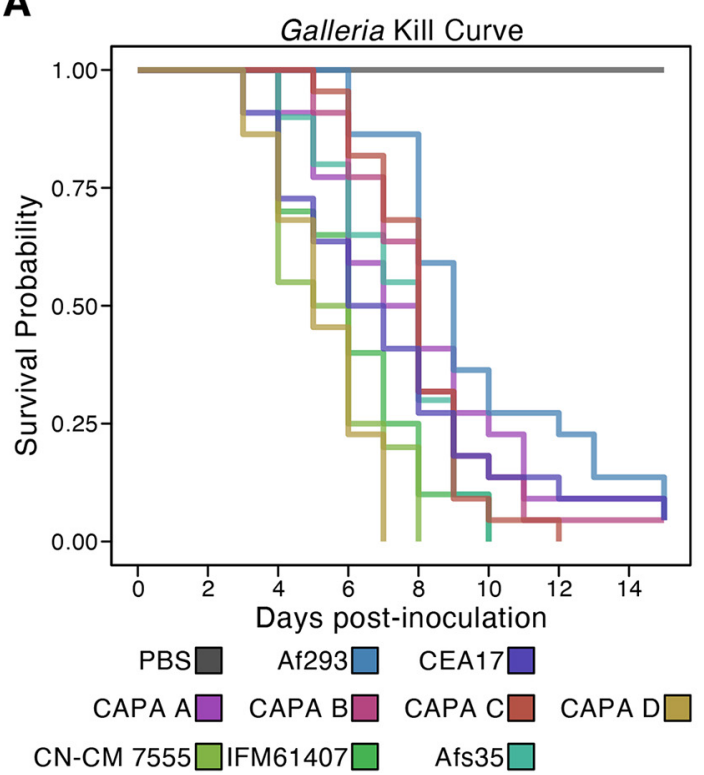

B

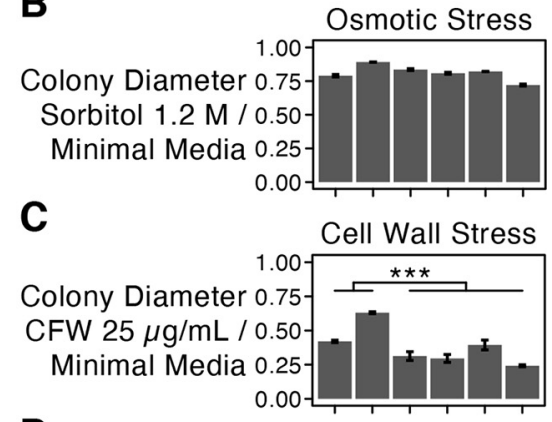

D

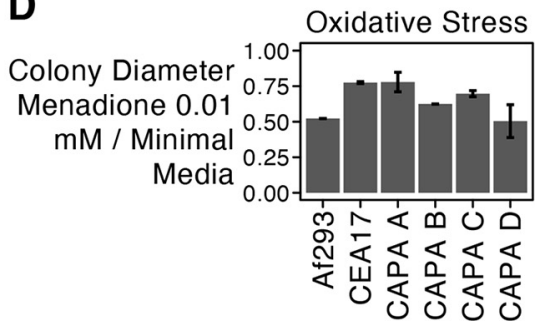

FIG 5 Strain heterogeneity among COVID-19-associated pulmonary aspergillosis (CAPA) isolates of Aspergillus fumigatus. (A) The virulence of the CAPA isolates, reference strains Af293 and CEA17, and clinical strains Afs35, CN-CM7555, and IFM61407 significantly varied in the Galleria moth model of disease $(P<0.001$; log-rank test; $\geq 20$ replicates per strain). Pairwise examinations revealed CAPA isolate D was significantly more virulent than all other strains (Benjamini-Hochberg adjusted $P<0.01$ when comparing CAPA isolate D to another isolate; logrank test) with the exception of clinical strains IFM61407 and CN-CM $7555(P=0.085$ and $P=0.386$, respectively). Growth of CAPA isolates and references strains Af293 and CEA17 in the presence of osmotic (B), cell wall (C), and oxidative stressors (D). Growth differences between CAPA isolates and reference strains Af293 and CEA17 were observed across all growth conditions $(P<0.001$; multifactor ANOVA). Pairwise differences were assessed using the post hoc Tukey's honestly significant difference (HSD) test and were only observed for growth in the presence of CFW at $25 \mu \mathrm{g} / \mathrm{ml}(P<0.001$; Tukey HSD test) in which the CAPA isolates did not grow as well as the reference isolates. To correct for strain heterogeneity in growth rates, radial growth in centimeters in the presence of stressors was divided by radial growth in centimeters in the absence of the stressor (MM only). Abbreviations of cell wall stressors are as follows: CFW, calcofluor white; CR, Congo red; CSP, caspofungin. Growth in the presence of other stressors is summarized in Fig. S4. Error bars in panels B to $D$ represent the average of \pm one standard deviation across three replicates.

and reference strains Af293 and CEA17 (Table 3). Following the guidelines of the Clinical and Laboratory Standards Institute (71), the CAPA isolates are not considered multidrug resistant.

Secondary metabolites can impact host biology and virulence $(30,72)$. Examination of secondary metabolite production revealed strain heterogeneity among CAPA isolates and reference strains $\mathrm{Af} 293$ and CEA10, a pyrG ${ }^{+}$and $a k u B^{\mathrm{KU}}{ }^{20+}$ strain that CEA17 is derived from (41). For example, principal-component analysis of chromatogram features revealed that CAPA isolate A was substantially different from other CAPA isolates along the first and second principal components, which capture $82.47 \%$ of the total variance, whereas the CAPA isolate D was substantially different from other CAPA isolates along the second and third principal components, which capture $38.64 \%$ of total variance (Fig. S5). Examination of the loadings plot, which identifies the individual secondary metabolites that contribute to the observed variation across strains, revealed gliotoxin and fumitremorgin as the largest contributors (Fig. S6). Measurement of relative abundance of biosynthesized gliotoxin and fumitremorgin, two secondary metabolites known to modulate host biology (30), showed the largest amount of fumitremorgin was biosynthesized by CAPA isolate A, and the largest amount of gliotoxin was biosynthesized by the Af293 strain, followed by CAPA isolate C (Fig. S6; Table 2).

In summary, we found the CAPA isolates have similar phenotypic profiles, with the exception of growth in the presence of calcofluor white and secondary metabolite 
TABLE 3 Antifungal drug susceptibility (MICs in $\mu \mathrm{g} / \mathrm{ml}$ ) of CAPA clinical isolates grown in minimal medium

\begin{tabular}{lllllll}
\hline Drug & Af293 & CEA17 & CAPA A & CAPA B & CAPA C & CAPA D \\
\hline Amphotericin B & 2 & 2 & $2-4$ & 2 & 2 & 2 \\
Voriconazole & 1 & $0.25-0.50$ & 0.5 & 0.5 & $0.25-0.50$ & 0.5 \\
Itraconazole & 0.5 & 0.5 & 0.5 & 0.5 & 0.5 & 0.5 \\
Posaconazole & 1 & 1 & 1 & 1 & 1 & 1 \\
\hline
\end{tabular}

biosynthesis, compared to reference strains, and virulence on par with the known range of $A$. fumigatus clinical strains.

In conclusion, the effects of secondary fungal infections in COVID-19 patients are only beginning to be understood. Our results revealed that CAPA isolates are generally, but not always, similar to $A$. fumigatus clinical reference strains. Notably, CAPA isolate $D$ was significantly more virulent than the other three CAPA isolates and two reference strains examined, but on par with other clinical strains. Taken together, these results are important to consider in the management of fungal infections among patients with COVID-19, especially those infected with A. fumigatus, and broaden our understanding of CAPA.

\section{MATERIALS AND METHODS}

Patient information and ethics approval. Patients were included into the FungiScope global registry for emerging invasive fungal infections (www.ClinicalTrials.gov, NCT 01731353). The clinical trial is approved by the Ethics Committee of the University of Cologne, Cologne, Germany (study ID: 05-102) (73). Since 2019, patients with invasive aspergillosis were also included.

DNA quality control, library preparation, and sequencing. Sample DNA concentration was measured by Qubit fluorometer and DNA integrity and purity by agarose gel electrophoresis. For each sample, 1 to $1.5 \mu \mathrm{g}$ of genomic DNA was randomly fragmented by Covaris and fragments with average sizes of 200 to $400 \mathrm{bp}$ were selected by Agencourt AMPure XP-Medium kit. The selected fragments were endrepaired, $3^{\prime}$ adenylated, ligated to adapters, and amplified by PCR. Double-stranded PCR products were recovered by the AxyPrep Mag PCR cleanup kit, and then heat denatured and circularized by using the splint oligonucleotide sequence. The single-strand circlular DNA (ssCir DNA) products were formatted as the final library and went through further QC procedures. The libraries were sequenced on the MGISEQ2000 platform.

Genome assembly and annotations. Short-read sequencing data of each sample were assembled using MaSuRCA, v3.4.1 (74). Each de novo genome assembly was annotated using the MAKER genome annotation pipeline, v2.31.11 (75), which integrates three $a b$ initio gene predictors: AUGUSTUS, v3.3.3 (76), GeneMark-ES, v4.59 (77), and SNAP, v2013-11-29 (78). Fungal protein sequences in the Swiss-Prot database (release 2020_02) were used as homology evidence for the genome annotation. The MAKER annotation process occurs in an iterative manner as described previously (79). In brief, for each genome, repeats were first soft-masked using RepeatMasker v4.1.0 (http://www.repeatmasker.org) with the library Repbase library release-20181026 and the "-species" parameter set to "Aspergillus fumigatus." GeneMarkES was then trained on the masked genome sequence using the self-training option ("-ES") and the branch model algorithm ("-fungus"), which is optimal for fungal genome annotation. On the other hand, an initial MAKER analysis was carried out where gene annotations were generated directly from homology evidence, and the resulting gene models were used to train both AUGUSTUS and SNAP. Once trained, the $a b$ initio predictors were used together with homology evidence to conduct a first round of full MAKER analysis. Resulting gene models supported by homology evidence were used to retrain AUGUSTUS and SNAP. A second round of MAKER analysis was conducted using the newly trained AUGUSTUS and SNAP parameters, and once again the resulting gene models with homology supports were used to retrain AUGUSTUS and SNAP. Finally, a third round of MAKER analysis was performed using the new AUGUSTUS and SNAP parameters to generate the final set of annotations for the genome. The completeness of de novo genome assemblies and ab initio gene predictions was assessed using BUSCO, v4.1.2 (80) using 4,191 preselected "nearly" universally single-copy orthologous genes from the Eurotiales database (eurotials_odb10.2019-11-20) in OrthoDB, v10.1 (81).

Polymorphism identification. To characterize and examine the putative impact of polymorphisms in the genomes of the CAPA isolates, we identified single nucleotide polymorphisms (SNPs), insertiondeletion polymorphisms (indels), and copy number (CN) polymorphisms. To do so, reads were first quality-trimmed and mapped to the genome of A. fumigatus Af293 (RefSeq assembly accession: GCF_000002655.1) following a previously established protocol (82). Specifically, reads were first qualitytrimmed with Trimmomatic v0.36 (83) using the following parameters: leading, 10; trailing, 10; slidingwindow, 4:20; minlen, 50. The resulting quality-trimmed reads were mapped to the $A$. fumigatus Af293 genome using the Burrows-Wheeler Aligner (BWA) v0.7.17 (84) with the mem parameter. Thereafter, 
mapped reads were converted to a sorted bam and mpileup format for polymorphism identification using SAMtools v.1.3.1 (85).

To identify SNPs and indels, mpileup files were used as input into VarScan v2.3.9 (86), with the mpileup2snp and mpileup2indel functions, respectively. To ensure only confident SNPs and indels were identified, a Fisher's exact test $P$ value threshold of 0.05 and minimum variant allele frequency of 0.75 were used. The resulting Variant Call Format files were used as input to snpEff v.4.3t (87), which predicted their functional impacts on gene function as high, moderate, or low. To identify CN variants, the sorted bam files were used as input into Control-FREEC v9.1 $(88,89)$. The coefficientOfVariation parameter was set to 0.062 and window size was automatically determined by Control-FREEC. To ensure high confidence in $\mathrm{CN}$ variant identification, a $P$ value threshold of 0.05 was used for both the Wilcoxon rank sum and Kolmogorov Smirnov tests.

To identify evidence of putative pseudogenization between reference strains A1163 and Af293, we used a previously established approach $(19,90)$. More specifically, we compared lengths of gene pairs as a proxy for pseudogenization. A gene was considered a putative pseudogene in one of the strains if the gene was $70 \%$ the length of its reciprocal best blast hit in the other strain.

Maximum likelihood molecular phylogenetics. To taxonomically identify the species of Aspergillus sequenced, we conducted molecular phylogenetic analysis of two different loci and two different data sets. In the first analysis, the nucleotide sequence of the alpha subunit of translation elongation factor EF-1, tef1 (NCBI accession: XM_745295.2), from the genome of A. fumigatus Af293 was used to extract other fungal tef1 sequences from NCBI's fungal nucleotide reference sequence database (downloaded July 2020) using the blastn function from NCBI's BLAST+, v2.3.0 (91). Tef1 sequences were extracted from the CAPA isolates by identifying their best BLAST hit. Sequences from the top 100 best BLAST hits in the fungal nucleotide reference sequence database and the four tef1 sequences from the CAPA isolates were aligned using MAFFT v7.402 (92) using previously described parameters (93) with slight modifications. Specifically, the following parameters were used: -op 1.0 -maxiterate 1000 -retree 1 -genafpair. The resulting alignment was trimmed using ClipKIT v0.1 (19) with default "gappy" mode. The trimmed alignment was then used to infer the evolutionary history of tef1 sequences using IQ-TREE2 (94). The best-fitting substitution model-TIM3 with empirical base frequencies, allowing for a proportion of invariable sites, and a discrete Gamma model $(95,96)$ with four rate categories (TIM3 $+\mathrm{F}+\mathrm{I}+\mathrm{G} 4)-$ was determined using the Bayesian information criterion. In the second analysis, the same process was used to conduct molecular phylogenetic analysis using calmodulin nucleotide sequences from Aspergillus section Fumigati species and Aspergillus clavatus, an outgroup taxon, using sequences from NCBI that were made available elsewhere (97). For calmodulin sequences, the best-fitting substitution model was TNe (98) with a discrete Gamma model with four rate categories (TNe+G4). Bipartition support was assessed using 5,000 ultrafast bootstrap support approximations (99).

To determine which strains of $A$. fumigatus the CAPA isolates were most similar to, we conducted phylogenomic analyses using the 50 Aspergillus proteomes. To do so, we first identified orthologous groups of genes across all 50 Aspergillus strains using OrthoFinder 2.3 .8 (100). OrthoFinder takes as input the proteome sequence files from multiple genomes and conducts all-versus-all sequence similarity searches using DIAMOND v0.9.24.125 (101). Our input included 50 total proteomes, where 47 were $A$. fumigatus, two were $A$. fischeri, and one was $A$. oerlinghausenensis $(40,42,45)$. OrthoFinder then clusters sequences into orthologous groups of genes using the graph-based Markov Clustering Algorithm (102). To maximize the number of single-copy orthologous groups of genes found across all input genomes, clustering granularity was explored by running 41 iterations of OrthoFinder that differed in their inflation parameter. Specifically, iterations of OrthoFinder inflation parameters were set to 1.0 to 5.0 with a step of 0.1. The lowest number of single-copy orthologous groups of genes was 3,399 when using an inflation parameter of 1.0; the highest number was 4,525 when using inflation parameter values of 3.8 and 4.1. We used the groups inferred using an inflation parameter of 3.8 .

Next, we built the phylogenomic data matrix and reconstructed evolutionary relationships among the 50 Aspergillus genomes. To do so, the protein sequences from 4,525 single-copy orthologous groups of genes were aligned using MAFFT v7.402 (92), with the following parameters: -bl 62 -op 1.0 -maxiterate 1000 -retree 1 -genafpair. Next, nucleotide sequences were threaded onto the protein alignments using function thread_dna in PhyKIT v0.0.1 (103). The resulting codon-based alignments were then trimmed using ClipKIT v0.1 (104), using the gappy mode. The resulting aligned and trimmed alignments were then concatenated into a single matrix with 7,133,367 sites using the PhyKIT function create_concat. To reconstruct the evolutionary history of the 50 Aspergillus genomes, a single best-fitting model of sequence substitution and rate heterogeneity was estimated across the entire matrix using IQ-TREE2 v.2.0.6 (94). The best-fitting model was determined to be a general time reversible model with empirical base frequencies and invariable sites with a discrete Gamma model with four rate categories $(G T R+F+I+G 4)(96,105-107)$ using the Bayesian information criterion. During tree search, the number of candidate trees maintained during maximum likelihood tree search was increased from five to ten. Five independent searches were conducted and the tree with the best log-likelihood score was chosen as the "best" phylogeny. Bipartition support was evaluated using 5,000 ultrafast bootstrap approximations (99).

Biosynthetic gene cluster prediction. To predict BGCs in the genomes of A. fumigatus strains Af293 and the CAPA isolates, gene boundaries inferred by MAKER were used as input into antiSMASH v4.1.0 (108). Using a previously published list of genes known to encode BGCs in the genome of $A$. fumigatus Af293 (42), BLAST-based searches using an expectation value threshold of $1 \times 10^{-10}$ were used to identify BGCs implicated in modulating host biology using NCBI's BLAST+ v2.3.0 (91). Among predicted BGCs that did not match the previously published list, we further examined their evolutionary history if 
at least $50 \%$ of genes showed similarity to species outside the genus Aspergillus, which is information provided in the antiSMASH output. Using these criteria, no evidence suggestive of horizontally acquired BGCs from distant relatives was detected.

Characterization of biosynthesized secondary metabolites. (i) General experimental procedures. HRESIMS experiments utilized a Thermo LTQ Orbitrap XL mass spectrometer equipped with an electrospray ionization source. A Waters Acquity UPLC (Waters Corp.) was utilized using a BEH $\mathrm{C}_{18} \mathrm{Col}_{-}$ umn $(1.7 \mu \mathrm{m} ; 50 \mathrm{~mm} \times 2.1 \mathrm{~mm})$ set to a temperature of $40^{\circ} \mathrm{C}$ and a flow rate of $0.3 \mathrm{ml} / \mathrm{min}$. The mobile phase consisted of a linear gradient of $\mathrm{CH}_{3} \mathrm{CN}-\mathrm{H}_{2} \mathrm{O}$ (both acidified with $0.1 \%$ formic acid), starting at $15 \%$ $\mathrm{CH}_{3} \mathrm{CN}$ and increasing linearly to $100 \% \mathrm{CH}_{3} \mathrm{CN}$ over $8 \mathrm{~min}$, with a $1.5 \mathrm{~min}$ hold before returning to the starting condition.

(ii) Growth and extraction of fungal cultures. To identify the chemical differences between the various A. fumigatus strains and isolates (Af293, CEA10, CAPA isolates A, B, C, and D), they were grown in a clinically relevant growth condition $\left(37^{\circ} \mathrm{C}\right)$ and extracted for chemometric analysis. Czapek Dox agar (Sigma-Aldrich) petri plates were inoculated with the asexual spores of each strain in biological triplicates. Subsequently, the plates were incubated at $37^{\circ} \mathrm{C}$ in the dark for 3 days. The cultures were extracted by chopping and transferring the agar to $20-\mathrm{ml}$ scintillation vials, adding $10 \mathrm{ml}$ of acetone, thoroughly shaking, and then letting the samples sit for $4 \mathrm{~h}$. Last, the cultures were filtered and evaporated to dryness under nitrogen gas.

(iii) Metabolomics analyses. Principal-component analysis (PCA) was performed on the ultraperformance liquid chromatography-mass spectrometry (UPLC-MS) data. Untargeted UPLC-MS data sets for each sample were individually aligned, filtered, and analyzed using MZmine 2.20 software (https:// sourceforge.net/projects/mzmine/) (109). Peak detection was achieved using the following parameters: noise level (absolute value), $1.5 \times 10^{5}$; minimum peak duration, $0.05 \mathrm{~min} ; \mathrm{m} / \mathrm{z}$ variation tolerance, 0.05 ; and $\mathrm{m} / \mathrm{z}$ intensity variation, $20 \%$. Peak list filtering and retention time alignment algorithms were used to refine peak detection. The join algorithm integrated all sample profiles into a data matrix using the following parameters: $\mathrm{m} / \mathrm{z}$ and retention time balance set at 10.0 each, $\mathrm{m} / \mathrm{z}$ tolerance set at 0.001 , and RT tolerance set at $0.5 \mathrm{~min}$. The resulting data matrix was exported to Excel (Microsoft) for analysis as a set of $\mathrm{m} / \mathrm{z}$-retention time pairs with individual peak areas detected in quadruplicate analyses. Samples that did not possess detectable quantities of a given marker ion were assigned a peak area of zero to maintain the same number of variables for all sample sets. lons that did not elute between 2 and 8 min and/or had an $\mathrm{m} / \mathrm{z}$ ratio less than 100 or greater than 1,200 Da were removed from analysis. Relative standard deviation was used to quantify variance between the technical replicate injections, which may differ slightly based on instrument variance. A cutoff of 1.0 was used at any given $\mathrm{m} / \mathrm{z}$-retention time pair across the technical replicate injections of one biological replicate and, if the variance was greater than the cutoff, it was assigned a peak area of zero (110). Final chemometric analysis, including data filtering and PCA, was conducted using Python. The PCA plots were generated using data from the averaged biological replicates from the petri dish cultures. Each biological replicate was plotted using averaged peak areas obtained across four replicate injections (technical replicates). The principal components (PC) were generated and processed via Scikit Learn decomposition and Pandas v0.25.3, Python libraries. The PCA data were plotted using Altair v4.1.0, Python graphing libraries. These data were converted into a dataframe via Pandas, and the PCs were created from the dataframe using Scikit Learn decomposition. The PCA scores and loadings plots were then plotted using the PCs dataframe that was generated from Scikit Learn.

Infection of Galleria mellonella. Survival curves ( $n \geq 20 /$ strain) were generated for Galleria mellonella infected with CAPA isolates A, B, C, and D. Phosphate-buffered saline (PBS) without asexual spores (conidia) was administered as a negative control. A log-rank test was used to examine strain heterogeneity, followed by pairwise comparisons with the Benjamini-Hochberg multitest correction (111). All the selected larvae of Galleria mellonella were in the final (sixth) instar larval stage of development, weighing 275 to $330 \mathrm{mg}$. Fresh conidia from each strain were harvested from minimal medium (MM) plates in PBS solution and filtered through a Miracloth (Calbiochem). For each strain, the spores were counted using a hemocytometer and the stock suspension was done at $2 \times 10^{8} \mathrm{conidia} / \mathrm{ml}$. The viability of the administered inoculum was determined by plating a serial dilution of the conidia on $\mathrm{MM}$ medium at $37^{\circ} \mathrm{C}$. $\mathrm{A}$ total of $5 \mu \mathrm{l}\left(1 \times 10^{6}\right.$ conidia/larva) from each stock suspension was inoculated per larva. The control group was composed of larvae inoculated with $5 \mu$ l of PBS to observe the killing due to physical trauma. The inoculum was performed using Hamilton syringe $(7000.5 \mathrm{KH})$ via the last left proleg. After infection, the larvae were maintained in petri dishes at $37^{\circ} \mathrm{C}$ in the dark and were scored daily. Larvae were considered dead by presenting the absence of movement in response to touch.

Growth assays. To examine growth conditions of the CAPA isolates and reference strains Af293 and CEA17, plates were inoculated with $10^{4}$ spores per strain and allowed to grow for 5 days on solid MM or MM supplemented with various concentrations of osmotic (sorbitol, $\mathrm{NaCl}$ ), cell wall (Congo red, calcofluor white, and caspofungin), and oxidative stress agents (menadione and t-butyl) at $37^{\circ} \mathrm{C}$. MM had $1 \%$ (wt/vol) glucose, original high-nitrate salts, trace elements, and a $\mathrm{pH}$ of 6.5 ; trace elements, vitamins, and nitrate salt compositions follow standards described elsewhere (112). To correct for strain heterogeneity in growth rates, radial growth in centimeters in the presence of stressors was divided by radial growth in centimeters in the absence of the stressor.

To determine the MICs of antifungal drugs in the CAPA isolates and reference strains Af293 and CEA17, strains were grown in 96-well plates at a concentration of $10^{4}$ spores/well in $200 \mu$ l of RPMI 1640 supplemented with increasing concentrations of amphotericin B, voriconazole, itraconazole, and posaconazole, according to the protocol elaborated by the Clinical and Laboratory Standards Institute (71). 
The MIC was defined as the lowest concentration of drugs that visually inhibited $100 \%$ fungal growth. Three independent experiments were carried out for each antifungal drug.

Data availability. Newly sequenced genomes assemblies, annotations, and raw short reads have been deposited to NCBI's GenBank database under BioProject accession PRJNA673120.

Supplementary data, including tables, figures, and files, additional copies of genome assemblies, annotations, and gene coordinates, raw data, including the genome assembly and annotations of all analyzed Aspergillus genomes, the aligned and trimmed phylogenetic and phylogenomic data matrices, polymorphisms identified in the present project, and predicted BGCs have been uploaded to figshare (10.6084/m9.figshare.13118549).

\section{ACKNOWLEDGMENTS}

We thank Joan Bennett, Amelia Barber, and Jorge Amich for reviewing this work and for their constructive feedback. We thank the Rokas and Goldman laboratories for support of this work and their helpful insight.

J.L.S. and A.R. are supported by the Howard Hughes Medical Institute through the James H. Gilliam Fellowships for Advanced Study Program. A.R. received additional support from a Discovery Grant from Vanderbilt University, the Burroughs Wellcome Fund, the National Science Foundation (DEB-1442113), and the National Institutes of Health/National Institute of Allergy and Infectious Diseases (R56 Al146096). G.H.G. and A.D. thank Fundação de Amparo à Pesquisa do Estado de São Paulo (FAPESP) grant numbers 2016/07870-9 and 2020/06151-4, and Conselho Nacional de Desenvolvimento Científico e Tecnológico (CNPq), both from Brazil. R.A.C.S. was supported by Fundação de Amparo à Pesquisa do Estado de São Paulo (FAPESP) grant numbers 2017/21983-3 and 2019/07526-4. X.Z. is supported by the Key-Area Research and Development Program of Guangdong Province (2018B020206001). F.F. has a Clinician Scientist Position supported by the Deans Office, Faculty of Medicine, University of Cologne. C.V. is supported by FAPESP grant number 2018/00715-3. S.L.K. was supported by the National Center for Complementary and Integrative Health, a component of the National Institutes of Health, under award number F31 AT010558.

O.A.C. is supported by the German Federal Ministry of Research and Education, is funded by the Deutsche Forschungsgemeinschaft (DFG, German Research Foundation) under Germany's Excellence Strategy (CECAD, EXC 2030, 390661388), and has received research grants from, is an advisor to, or received lecture honoraria from Actelion, Allecra Therapeutics, Al-Jazeera Pharmaceuticals, Amplyx, Astellas, Basilea, Biosys, Cidara, Da Volterra, Entasis, F2G, Gilead, Grupo Biotoscana, IQVIA, Janssen, Matinas, Medicines Company, MedPace, Melinta Therapeutics, Menarini, Merck/MSD, Mylan, Nabriva, Noxxon, Octapharma, Paratek, Pfizer, PSI, Roche Diagnostics, Scynexis, and Shionogi. P. K. has received nonfinancial scientific grants from Miltenyi Biotec $\mathrm{GmbH}$, Bergisch Gladbach, Germany, and the Cologne Excellence Cluster on Cellular Stress Responses in Aging-Associated Diseases, University of Cologne, Cologne, Germany, and received lecture honoraria from or is advisor to Akademie für Infektionsmedizin e.V., Astellas Pharma, European Confederation of Medical Mycology, Gilead Sciences, GPR Academy Ruesselsheim, MSD Sharp \& Dohme GmbH, Noxxon N.V., and University Hospital, LMU Munich outside the submitted work. A. R. is a Scientific Consultant for LifeMine Therapeutics, Inc. N.H.O. is on the Scientific Advisory Board of Mycosynthetix, Inc.

\section{REFERENCES}

1. Sohrabi C, Alsafi Z, O'Neill N, Khan M, Kerwan A, Al-Jabir A, losifidis C, Agha R. 2020. World Health Organization declares global emergency: a review of the 2019 novel coronavirus (COVID-19). Int J Surg 76:71-76. https://doi.org/10.1016/j.ijsu.2020.02.034.

2. Cox MJ, Loman N, Bogaert D, O'Grady J. 2020. Co-infections: potentially lethal and unexplored in COVID-19. Lancet Microbe 1:e11. https://doi .org/10.1016/S2666-5247(20)30009-4.

3. Brüggemann RJ, van de Veerdonk FL, Verweij PE. 2020. The challenge of managing COVID-19 associated pulmonary aspergillosis. Clin Infect Dis ciaa1211. https://doi.org/10.1093/cid/ciaa1211.
4. Zhou P, Liu Z, Chen Y, Xiao Y, Huang X, Fan X-G. 2020. Bacterial and fungal infections in COVID-19 patients: a matter of concern. Infect Control Hosp Epidemiol 41:1124-1125. https://doi.org/10.1017/ice.2020.156.

5. Maclntyre CR, Chughtai AA, Barnes M, Ridda I, Seale H, Toms R, Heywood A. 2018. The role of pneumonia and secondary bacterial infection in fatal and serious outcomes of pandemic influenza a(H1N1)pdm09. BMC Infect Dis 18:637. https://doi.org/10.1186/s12879-018-3548-0.

6. Langford BJ, So M, Raybardhan S, Leung V, Westwood D, MacFadden DR, Soucy J-PR, Daneman N. 2020. Bacterial co-infection and secondary infection in patients with COVID-19: a living rapid review and meta- 
analysis. Clin Microbiol Infect 26:1622-1629. https://doi.org/10.1016/j .cmi.2020.07.016.

7. Nasir N, Farooqi J, Mahmood SF, Jabeen K. 2020. COVID-19-associated pulmonary aspergillosis (CAPA) in patients admitted with severe COVID-19 pneumonia: an observational study from Pakistan. Mycoses 63:766-770. https://doi.org/10.1111/myc.13135.

8. Koehler P, Cornely OA, Böttiger BW, Dusse F, Eichenauer DA, Fuchs F, Hallek M, Jung N, Klein F, Persigehl T, Rybniker J, Kochanek M, Böll B, Shimabukuro-Vornhagen A. 2020. COVID-19 associated pulmonary aspergillosis. Mycoses 63:528-534. https://doi.org/10.1111/myc.13096.

9. Chen N, Zhou M, Dong X, Qu J, Gong F, Han Y, Qiu Y, Wang J, Liu Y, Wei Y, Xia J, Yu T, Zhang X, Zhang L. 2020. Epidemiological and clinical characteristics of 99 cases of 2019 novel coronavirus pneumonia in Wuhan, China: a descriptive study. Lancet 395:507-513. https://doi.org/10.1016/ S0140-6736(20)30211-7.

10. Rutsaert L, Steinfort N, Van Hunsel T, Bomans $P$, Naesens R, Mertes $H$, Dits H, Van Regenmortel N. 2020. COVID-19-associated invasive pulmonary aspergillosis. Ann Intensive Care 10:71. https://doi.org/10.1186/ s13613-020-00686-4.

11. Alanio A, Dellière S, Fodil S, Bretagne S, Mégarbane B. 2020. Prevalence of putative invasive pulmonary aspergillosis in critically ill patients with COVID-19. Lancet Respir Med 8:e48-e49. https://doi.org/10.1016/S2213 $-2600(20) 30237-X$.

12. van Arkel ALE, Rijpstra TA, Belderbos HNA, van Wijngaarden $P$, Verweij PE, Bentvelsen RG. 2020. COVID-19-associated Pulmonary Aspergillosis. Am J Respir Crit Care Med 202:132-135. https://doi.org/10.1164/rccm .202004-1038LE.

13. Gangneux J-P, Reizine F, Guegan H, Pinceaux K, Le Balch P, Prat E, Pelletier R, Belaz S, Le Souhaitier M, Le Tulzo Y, Seguin P, Lederlin M, Tadié J-M, Robert-Gangneux F. 2020. Is the COVID-19 pandemic a good time to include Aspergillus molecular detection to categorize aspergillosis in ICU patients? JoF 6:105. https://doi.org/10.3390/jof6030105.

14. Armstrong-James D, Youngs J, Bicanic T, Abdolrasouli A, Denning DW, Johnson E, Mehra V, Pagliuca T, Patel B, Rhodes J, Schelenz S, Shah A, van de Veerdonk FL, Verweij PE, White PL, Fisher MC. 2020. Confronting and mitigating the risk of COVID-19 associated pulmonary aspergillosis. Eur Respir J 56:2002554. https://doi.org/10.1183/13993003.02554-2020.

15. Bongomin F, Gago S, Oladele R, Denning D. 2017. Global and multinational prevalence of fungal diseases-estimate precision. JoF 3:57. https://doi.org/10.3390/jof3040057.

16. Latgé J-P, Chamilos G. 2019. Aspergillus fumigatus and aspergillosis in 2019. Clin Microbiol Rev 33:e00140-18. https://doi.org/10.1128/CMR $.00140-18$

17. Rokas A, Mead ME, Steenwyk JL, Oberlies NH, Goldman GH. 2020. Evolving moldy murderers: Aspergillus section Fumigati as a model for studying the repeated evolution of fungal pathogenicity. PLoS Pathog 16: e1008315. https://doi.org/10.1371/journal.ppat.1008315.

18. dos Santos RAC, Steenwyk JL, Rivero-Menendez O, Mead ME, Silva LP, Bastos RW, Alastruey-Izquierdo A, Goldman GH, Rokas A. 2020. Genomic and phenotypic heterogeneity of clinical isolates of the human pathogens Aspergillus fumigatus, Aspergillus lentulus, and Aspergillus fumigatiaffinis. Front Genet 11:459. https://doi.org/10.3389/fgene.2020.00459.

19. Steenwyk JL, Lind AL, Ries LNA, dos Reis TF, Silva LP, Almeida F, Bastos RW, de Fraga da Silva TFC, Bonato VLD, Pessoni AM, Rodrigues F, Raja HA, Knowles SL, Oberlies NH, Lagrou K, Goldman GH, Rokas A. 2020. Pathogenic allodiploid hybrids of Aspergillus fungi. Curr Biol 30:2495-2507.e7. https://doi.org/10.1016/j.cub.2020.04.071.

20. Bastos RW, Valero C, Silva LP, Schoen T, Drott M, Brauer V, Silva-Rocha R, Lind A, Steenwyk JL, Rokas A, Rodrigues F, Resendiz-Sharpe A, Lagrou K, Marcet-Houben M, Gabaldón T, McDonnell E, Reid I, Tsang A, Oakley BR, Loures FV, Almeida F, Huttenlocher A, Keller NP, Ries LNA, Goldman GH. 2020. Functional characterization of clinical isolates of the opportunistic fungal pathogen Aspergillus nidulans. mSphere 5:e00153-20. https://doi .org/10.1128/mSphere.00153-20

21. Kamei K, Watanabe A. 2005. Aspergillus mycotoxins and their effect on the host. Med Mycol 43:95-99. https://doi.org/10.1080/13693780500051547.

22. Tekaia F, Latgé J-P. 2005. Aspergillus fumigatus: saprophyte or pathogen? Curr Opin Microbiol 8:385-392. https://doi.org/10.1016/j.mib.2005 .06.017.

23. Abad A, Victoria Fernández-Molina J, Bikandi J, Ramírez A, Margareto J, Sendino J, Luis Hernando F, Pontón J, Garaizar J, Rementeria A. 2010. What makes Aspergillus fumigatus a successful pathogen? Genes and molecules involved in invasive aspergillosis. Rev Iberoam Micol 27:155-182. https://doi.org/10.1016/j.riam.2010.10.003
24. Grahl N, Shepardson KM, Chung D, Cramer RA. 2012. Hypoxia and fungal pathogenesis: to air or not to air? Eukaryot Cell 11:560-570. https://do .org/10.1128/EC.00031-12.

25. Shwab EK, Bok JW, Tribus M, Galehr J, Graessle S, Keller NP. 2007. Histone deacetylase activity regulates chemical diversity in Aspergillus. Eukaryot Cell 6:1656-1664. https://doi.org/10.1128/EC.00186-07.

26. Losada L, Ajayi O, Frisvad JC, Yu J, Nierman WC. 2009. Effect of competition on the production and activity of secondary metabolites in Aspergillus species. Med Mycol 47:S88-S96. https://doi.org/10.1080/13693780802409542.

27. Yin W-B, Baccile JA, Bok JW, Chen Y, Keller NP, Schroeder FC. 2013. A nonribosomal peptide synthetase-derived iron(III) complex from the pathogenic fungus Aspergillus fumigatus. J Am Chem Soc 135:2064-2067. https://doi .org/10.1021/ja311145n.

28. Wiemann $P$, Lechner BE, Baccile JA, Velk TA, Yin W-B, Bok JW, Pakala S Losada L, Nierman WC, Schroeder FC, Haas H, Keller NP. 2014. Perturbations in small molecule synthesis uncovers an iron-responsive secondary metabolite network in Aspergillus fumigatus. Front Microbiol 5:530. https://doi.org/10.3389/fmicb.2014.00530.

29. Knox BP, Blachowicz A, Palmer JM, Romsdahl J, Huttenlocher A, Wang CCC, Keller NP, Venkateswaran K. 2016. Characterization of Aspergillus fumigatus isolates from air and surfaces of the International Space Station. mSphere 1:e00227-16. https://doi.org/10.1128/mSphere.00227-16.

30. Raffa N, Keller NP. 2019. A call to arms: mustering secondary metabolites for success and survival of an opportunistic pathogen. PLoS Pathog 15 e1007606. https://doi.org/10.1371/journal.ppat.1007606.

31. Blachowicz A, Raffa N, Bok JW, Choera T, Knox B, Lim FY, Huttenlocher A, Wang CCC, Venkateswaran K, Keller NP. 2020. Contributions of spore secondary metabolites to UV-C protection and virulence vary in different Aspergillus fumigatus strains. mBio 11:e03415-19. https://doi.org/10.1128/ mBio.03415-19.

32. Kowalski CH, Kerkaert JD, Liu K-W, Bond MC, Hartmann R, Nadell CD, Stajich JE, Cramer RA. 2019. Fungal biofilm morphology impacts hypoxia fitness and disease progression. Nat Microbiol 4:2430-2441. https://doi .org/10.1038/s41564-019-0558-7.

33. Howard SJ, Arendrup MC. 2011. Acquired antifungal drug resistance in Aspergillus fumigatus: epidemiology and detection. Med Mycol 49: S90-S95. https://doi.org/10.3109/13693786.2010.508469.

34. Chamilos G, Kontoyiannis DP. 2005. Update on antifungal drug resistance mechanisms of Aspergillus fumigatus. Drug Resist Updat 8:344-358. https:// doi.org/10.1016/j.drup.2006.01.001.

35. Chowdhary A, Sharma C, Hagen F, Meis JF. 2014. Exploring azole antifungal drug resistance in Aspergillus fumigatus with special reference to resistance mechanisms. Future Microbiol 9:697-711. https://doi.org/10.2217/ fmb.14.27.

36. Sewell TR, Zhu J, Rhodes J, Hagen F, Meis JF, Fisher MC, Jombart T. 2019. Nonrandom distribution of azole resistance across the global population of Aspergillus fumigatus. mBio 10:e00392-19. https://doi.org/10.1128/ mBio.00392-19.

37. Keller NP. 2017. Heterogeneity confounds establishment of "a" model microbial strain. mBio 8:e00135-17. https://doi.org/10.1128/mBio.00135-17.

38. Kowalski CH, Beattie SR, Fuller KK, McGurk EA, Tang Y-W, Hohl TM, Obar $\mathrm{J}$, Cramer RA. 2016. Heterogeneity among isolates reveals that fitness in low oxygen correlates with Aspergillus fumigatus virulence. mBio 7 : e01515-16. https://doi.org/10.1128/mBio.01515-16.

39. Ries LNA, Steenwyk JL, de Castro PA, de Lima PBA, Almeida F, de Assis LJ, Manfiolli AO, Takahashi-Nakaguchi A, Kusuya Y, Hagiwara D, Takahashi H, Wang X, Obar JJ, Rokas A, Goldman GH. 2019. Nutritional heterogeneity among Aspergillus fumigatus strains has consequences for virulence in a strain- and host-dependent manner. Front Microbiol 10:854. https:// doi.org/10.3389/fmicb.2019.00854.

40. Steenwyk JL, Mead ME, Knowles SL, Raja HA, Roberts CD, Bader O, Houbraken J, Goldman GH, Oberlies NH, Rokas A. 2020. Variation among biosynthetic gene clusters, secondary metabolite profiles, and cards of virulence across Aspergillus species. Genetics 216:481-497. https://doi .org/10.1534/genetics.120.303549.

41. Bertuzzi M, van Rhijn N, Krappmann S, Bowyer P, Bromley MJ, Bignell EM. 2021. On the lineage of Aspergillus fumigatus isolates in common laboratory use. Med Mycol 59:7-13. https://doi.org/10.1093/mmy/myaa075.

42. Lind AL, Wisecaver JH, Lameiras C, Wiemann P, Palmer JM, Keller NP, Rodrigues F, Goldman GH, Rokas A. 2017. Drivers of genetic diversity in secondary metabolic gene clusters within a fungal species. PLoS Biol 15: e2003583. https://doi.org/10.1371/journal.pbio.2003583.

43. Abdolrasouli A, Rhodes J, Beale MA, Hagen F, Rogers TR, Chowdhary A, Meis JF, Armstrong-James D, Fisher MC. 2015. Genomic context of azole 
resistance mutations in Aspergillus fumigatus determined using wholegenome sequencing. mBio 6:e00939-15. https://doi.org/10.1128/mBio .00939-15.

44. Nierman WC, Pain A, Anderson MJ, Wortman JR, Kim HS, Arroyo J, Berriman M, Abe K, Archer DB, Bermejo C, Bennett J, Bowyer P, Chen D, Collins M, Coulsen R, Davies R, Dyer PS, Farman M, Fedorova N, Fedorova N, Feldblyum TV, Fischer R, Fosker N, Fraser A, García JL, García MJ, Goble A, Goldman GH, Gomi K, Griffith-Jones S, Gwilliam R, Haas B, Haas $H$, Harris D, Horiuchi H, Huang J, Humphray S, Jiménez J, Keller N, Khouri H, Kitamoto K, Kobayashi T, Konzack S, Kulkarni R, Kumagai T, Lafton A, Latgé J-P, Li W, Lord A, Lu C, et al. 2005. Genomic sequence of the pathogenic and allergenic filamentous fungus Aspergillus fumigatus. Nature 438:1151-1156. https://doi.org/10.1038/nature04332.

45. Fedorova ND, Khaldi N, Joardar VS, Maiti R, Amedeo P, Anderson MJ, Crabtree J, Silva JC, Badger JH, Albarraq A, Angiuoli S, Bussey H, Bowyer P, Cotty PJ, Dyer PS, Egan A, Galens K, Fraser-Liggett CM, Haas BJ, Inman JM, Kent R, Lemieux S, Malavazi I, Orvis J, Roemer T, Ronning CM, Sundaram JP, Sutton G, Turner G, Venter JC, White OR, Whitty BR, Youngman P, Wolfe KH, Goldman GH, Wortman JR, Jiang B, Denning DW, Nierman WC. 2008. Genomic islands in the pathogenic filamentous fungus Aspergillus fumigatus. PLoS Genet 4:e1000046. https://doi.org/ 10.1371/journal.pgen.1000046.

46. Paul S, Zhang A, Ludeña Y, Villena GK, Yu F, Sherman DH, GutiérrezCorrea M. 2017. Insights from the genome of a high alkaline cellulase producing Aspergillus fumigatus strain obtained from Peruvian Amazon rainforest. J Biotechnol 251:53-58. https://doi.org/10.1016/j.jbiotec.2017 .04.010.

47. Liu D, Zhang R, Yang X, Wu H, Xu D, Tang Z, Shen Q. 2011. Thermostable cellulase production of Aspergillus fumigatus Z5 under solid-state fermentation and its application in degradation of agricultural wastes. Internat Biodeterior Biodegrad 65:717-725. https://doi.org/10.1016/j ibiod.2011.04.005.

48. Mead ME, Knowles SL, Raja HA, Beattie SR, Kowalski CH, Steenwyk JL, Silva LP, Chiaratto J, Ries LNA, Goldman GH, Cramer RA, Oberlies NH, Rokas A. 2019. Characterizing the pathogenic, genomic, and chemical traits of Aspergillus fischeri, a close relative of the major human fungal pathogen Aspergillus fumigatus. mSphere 4:e00018-19. https://doi.org/ 10.1128/mSphere.00018-19.

49. Kjærbølling I, Vesth TC, Frisvad JC, Nybo JL, Theobald S, Kuo A, Bowyer P, Matsuda Y, Mondo S, Lyhne EK, Kogle ME, Clum A, Lipzen A, Salamov A, Ngan CY, Daum C, Chiniquy J, Barry K, LaButti K, Haridas S, Simmons BA, Magnuson JK, Mortensen UH, Larsen TO, Grigoriev IV, Baker SE, Andersen MR. 2018. Linking secondary metabolites to gene clusters through genome sequencing of six diverse Aspergillus species. Proc Natl Acad Sci U S A 115:E753-E761. https://doi.org/10.1073/pnas.1715954115.

50. Urban M, Cuzick A, Seager J, Wood V, Rutherford K, Venkatesh SY, De Silva N, Martinez MC, Pedro H, Yates AD, Hassani-Pak K, HammondKosack KE. 2019. PHI-base: the pathogen-host interactions database. Nucleic Acids Res 48:D613-D620. https://doi.org/10.1093/nar/gkz904.

51. Bignell E, Cairns TC, Throckmorton K, Nierman WC, Keller NP. 2016. Secondary metabolite arsenal of an opportunistic pathogenic fungus. Philos Trans R Soc B 371:20160023. https://doi.org/10.1098/rstb.2016.0023.

52. Puértolas-Balint F, Rossen JWA, Oliveira dos Santos C, Chlebowicz MMA, Raangs EC, van Putten ML, Sola-Campoy PJ, Han L, Schmidt M, GarcíaCobos S. 2019. Revealing the virulence potential of clinical and environmental Aspergillus fumigatus isolates using whole-genome sequencing. Front Microbiol 10:1970. https://doi.org/10.3389/fmicb.2019.01970.

53. Pennerman KK, Yin G, Glenn AE, Bennett JW. 2020. Identifying candidate Aspergillus pathogenicity factors by annotation frequency. BMC Microbiol 20:342. https://doi.org/10.1186/s12866-020-02031-y.

54. Tomee JF, Kauffman HF. 2000. Putative virulence factors of Aspergillus fumigatus. Clin Exp Allergy 30:476-484. https://doi.org/10.1046/j.1365 $-2222.2000 .00796 . x$.

55. Askew DS. 2008. Aspergillus fumigatus: virulence genes in a street-smart mold. Curr Opin Microbiol 11:331-337. https://doi.org/10.1016/j.mib 2008.05.009.

56. O'Hanlon KA, Cairns T, Stack D, Schrettl M, Bignell EM, Kavanagh K, Miggin SM, O'Keeffe G, Larsen TO, Doyle S. 2011. Targeted disruption of nonribosomal peptide synthetase pes3 augments the virulence of Aspergillus fumigatus. Infect Immun 79:3978-3992. https://doi.org/10 .1128/IAI.00192-11.

57. Johns A, Scharf DH, Gsaller F, Schmidt H, Heinekamp T, Straßburger M, Oliver JD, Birch M, Beckmann N, Dobb KS, Gilsenan J, Rash B, Bignell E, Brakhage AA, Bromley MJ. 2017. A nonredundant phosphopantetheinyl transferase, PptA, is a novel antifungal target that directs secondary metabolite, siderophore, and lysine biosynthesis in Aspergillus fumigatus and is critical for pathogenicity. mBio 8:e01504-16. https://doi.org/10 .1128/mBio.01504-16.

58. Mitsuguchi H, Seshime Y, Fujii I, Shibuya M, Ebizuka Y, Kushiro T. 2009. Biosynthesis of steroidal antibiotic fusidanes: functional analysis of oxidosqualene cyclase and subsequent tailoring enzymes from Aspergillus fumigatus. J Am Chem Soc 131:6402-6411. https://doi.org/10.1021/ ja8095976.

59. Kerr SC, Fischer GJ, Sinha M, McCabe O, Palmer JM, Choera T, Yun Lim F, Wimmerova M, Carrington SD, Yuan S, Lowell CA, Oscarson S, Keller NP, Fahy JV. 2016. FleA expression in Aspergillus fumigatus is recognized by fucosylated structures on mucins and macrophages to prevent lung infection. PLoS Pathog 12:e1005555. https://doi.org/10.1371/journal .ppat.1005555.

60. Valsecchi I, Sarikaya-Bayram Ö, Wong Sak Hoi J, Muszkieta L, Gibbons J, Prevost M-C, Mallet A, Krijnse-Locker J, Ibrahim-Granet O, Mouyna I, Carr P, Bromley M, Aimanianda V, Yu J-H, Rokas A, Braus GH, Saveanu C, Bayram Ö, Latgé JP. 2017. MybA, a transcription factor involved in conidiation and conidial viability of the human pathogen Aspergillus fumigatus. Mol Microbiol 105:880-900. https://doi.org/10.1111/mmi.13744.

61. Vargas-Muñiz JM, Renshaw $H$, Richards AD, Lamoth F, Soderblom EJ, Moseley MA, Juvvadi PR, Steinbach WJ. 2015. The Aspergillus fumigatus septins play pleiotropic roles in septation, conidiation, and cell wall stress, but are dispensable for virulence. Fungal Genet Biol 81:41-51. https://doi.org/10.1016/j.fgb.2015.05.014.

62. Hu W, Sillaots S, Lemieux S, Davison J, Kauffman S, Breton A, Linteau A, Xin C, Bowman J, Becker J, Jiang B, Roemer T. 2007. Essential gene identification and drug target prioritization in Aspergillus fumigatus. PLoS Pathog 3:e24. https://doi.org/10.1371/journal.ppat.0030024.

63. Paris S, Wysong D, Debeaupuis J-P, Shibuya K, Philippe B, Diamond RD, Latgé J-P. 2003. Catalases of Aspergillus fumigatus. Infect Immun 71:3551-3562. https://doi.org/10.1128/iai.71.6.3551-3562.2003.

64. González-Lobato L, Real R, Prieto JG, Álvarez AI, Merino G. 2010. Differential inhibition of murine Bcrp1/Abcg2 and human BCRP/ABCG2 by the mycotoxin fumitremorgin C. Eur J Pharmacol 644:41-48. https://doi.org/ 10.1016/j.ejphar.2010.07.016.

65. Gauthier T, Wang X, Sifuentes Dos Santos J, Fysikopoulos A, Tadrist S, Canlet C, Artigot MP, Loiseau N, Oswald IP, Puel O. 2012. Trypacidin, a spore-borne toxin from Aspergillus fumigatus, is cytotoxic to lung cells. PLoS One 7:e29906. https://doi.org/10.1371/journal.pone.0029906.

66. Ishikawa M, Ninomiya T, Akabane H, Kushida N, Tsujiuchi G, Ohyama M, Gomi S, Shito K, Murata T. 2009. Pseurotin A and its analogues as inhibitors of immunoglobuline $E$ production. Bioorg Med Chem Lett 19:1457-1460. https://doi.org/10.1016/j.bmcl.2009.01.029.

67. Fallon JP, Reeves EP, Kavanagh K. 2010. Inhibition of neutrophil function following exposure to the Aspergillus fumigatus toxin fumagillin. J Med Microbiol 59:625-633. https://doi.org/10.1099/jmm.0.018192-0.

68. Fallon JP, Reeves EP, Kavanagh K. 2011. The Aspergillus fumigatus toxin fumagillin suppresses the immune response of Galleria mellonella larvae by inhibiting the action of haemocytes. Microbiology 157:1481-1488. https://doi.org/10.1099/mic.0.043786-0.

69. Takahashi-Nakaguchi A, Muraosa Y, Hagiwara D, Sakai K, Toyotome T, Watanabe A, Kawamoto S, Kamei K, Gonoi T, Takahashi H. 2015. Genome sequence comparison of Aspergillus fumigatus strains isolated from patients with pulmonary aspergilloma and chronic necrotizing pulmonary aspergillosis. Med Mycol 53:353-360. https://doi.org/10.1093/mmy/ myv003.

70. Garcia-Rubio R, Monzon S, Alcazar-Fuoli L, Cuesta I, Mellado E. 2018. Genome-wide comparative analysis of Aspergillus fumigatus strains: the reference genome as a matter of concern. Genes (Basel) 9:363. https:// doi.org/10.3390/genes9070363.

71. Clinical and Laboratory Standards Institute. 2008. M38-A2 reference method for broth dilution antifungal susceptibility testing of filamentous fungi; approved standard, Second Edition. Clinical and Laboratory Standards Institute, Wayne, PA.

72. Sugui JA, Pardo J, Chang YC, Zarember KA, Nardone G, Galvez EM, Müllbacher A, Gallin Jl, Simon MM, Kwon-Chung KJ. 2007. Gliotoxin is a virulence factor of Aspergillus fumigatus: gliP deletion attenuates virulence in mice immunosuppressed with hydrocortisone. Eukaryot Cell 6:1562-1569. https://doi.org/10.1128/EC.00141-07.

73. Seidel D, Durán Graeff LA, Vehreschild MJGT, Wisplinghoff $H$, Ziegler $M$, Vehreschild JJ, Liss B, Hamprecht A, Köhler P, Racil Z, Klimko N, Sheppard DC, Herbrecht R, Chowdhary A, Cornely OA, FungiScope Group. 2017. 
FungiScope ${ }^{\mathrm{TM}}$-global emerging fungal infection registry. Mycoses 60:508-516. https://doi.org/10.1111/myc.12631.

74. Zimin AV, Marçais G, Puiu D, Roberts M, Salzberg SL, Yorke JA. 2013. The MaSuRCA genome assembler. Bioinformatics 29:2669-2677. https://doi .org/10.1093/bioinformatics/btt476.

75. Holt C, Yandell M. 2011. MAKER2: an annotation pipeline and genomedatabase management tool for second-generation genome projects. BMC Bioinformatics 12:491. https://doi.org/10.1186/1471-2105-12-491.

76. Stanke M, Waack S. 2003. Gene prediction with a hidden Markov model and a new intron submodel. Bioinformatics 19:ii215-ii225. https://doi .org/10.1093/bioinformatics/btg1080.

77. Besemer J, Borodovsky M. 2005. GeneMark: web software for gene finding in prokaryotes, eukaryotes and viruses. Nucleic Acids Res 33: W451-W454. https://doi.org/10.1093/nar/gki487.

78. Korf I. 2004. Gene finding in novel genomes. BMC Bioinformatics 5:59. https://doi.org/10.1186/1471-2105-5-59.

79. Shen X-X, Opulente DA, Kominek J, Zhou X, Steenwyk JL, Buh KV, Haase $M A B$, Wisecaver JH, Wang M, Doering DT, Boudouris JT, Schneider RM, Langdon QK, Ohkuma M, Endoh R, Takashima M, Manabe R, Čadež N, Libkind D, Rosa CA, DeVirgilio J, Hulfachor AB, Groenewald M, Kurtzman $\mathrm{CP}$, Hittinger CT, Rokas A. 2018. Tempo and mode of genome evolution in the budding yeast subphylum. Cell 175:1533-1545.e20. https://doi .org/10.1016/j.cell.2018.10.023.

80. Waterhouse RM, Seppey M, Simão FA, Manni M, loannidis $P$, Klioutchnikov G, Kriventseva EV, Zdobnov EM. 2018. BUSCO applications from quality assessments to gene prediction and phylogenomics. Mol Biol Evol 35:543-548. https://doi.org/10.1093/molbev/msx319.

81. Waterhouse RM, Tegenfeldt F, Li J, Zdobnov EM, Kriventseva EV. 2013. OrthoDB: a hierarchical catalog of animal, fungal and bacterial orthologs. Nucleic Acids Res 41:D358-D365. https://doi.org/10.1093/nar/gks1116.

82. Steenwyk J, Rokas A. 2017. Extensive copy number variation in fermentation-related genes among Saccharomyces cerevisiae wine strains. G3 (Bethesda) 7:1475-1485. https://doi.org/10.1534/g3.117.040105.

83. Bolger AM, Lohse M, Usadel B. 2014. Trimmomatic: a flexible trimmer for Illumina sequence data. Bioinformatics 30:2114-2120. https://doi.org/10 .1093/bioinformatics/btu170.

84. Li H. 2013. Aligning sequence reads, clone sequences and assembly contigs with BWA-MEM. arXiv https://arxiv.org/abs/1303.3997.

85. Li H, Handsaker B, Wysoker A, Fennell T, Ruan J, Homer N, Marth G, Abecasis G, Durbin R, 1000 Genome Project Data Processing Subgroup. 2009. The Sequence Alignment/Map format and SAMtools. Bioinformatics 25:2078-2079. https://doi.org/10.1093/bioinformatics/btp352.

86. Koboldt DC, Zhang Q, Larson DE, Shen D, McLellan MD, Lin L, Miller CA, Mardis ER, Ding L, Wilson RK. 2012. VarScan 2: somatic mutation and copy number alteration discovery in cancer by exome sequencing. Genome Res 22:568-576. https://doi.org/10.1101/gr.129684.111.

87. Cingolani P, Platts A, Wang LL, Coon M, Nguyen T, Wang L, Land SJ, Lu X, Ruden DM. 2012. A program for annotating and predicting the effects of single nucleotide polymorphisms, SnpEff: SNPs in the genome of Drosophila melanogaster strain w1118; iso-2; iso-3. Fly (Austin) 6:80-92. https://doi.org/10.4161/fly.19695.

88. Boeva V, Zinovyev A, Bleakley K, Vert JP, Janoueix-Lerosey I, Delattre O, Barillot E. 2011. Control-free calling of copy number alterations in deep-sequencing data using GC-content normalization. Bioinformatics 27:268-269. https://doi.org/10.1093/bioinformatics/btq635.

89. Boeva V, Popova T, Bleakley K, Chiche P, Cappo J, Schleiermacher G, Janoueix-Lerosey I, Delattre O, Barillot E. 2012. Control-FREEC: a tool for assessing copy number and allelic content using next-generation sequencing data. Bioinformatics 28:423-425. https://doi.org/10.1093/ bioinformatics/btr670.

90. Ortiz-Merino RA, Kuanyshev N, Braun-Galleani S, Byrne KP, Porro D, Branduardi P, Wolfe KH. 2017. Evolutionary restoration of fertility in an interspecies hybrid yeast, by whole-genome duplication after a failed mating-type switch. PLoS Biol 15:e2002128. https://doi.org/10 .1371/journal.pbio.2002128.

91. Camacho C, Coulouris G, Avagyan V, Ma N, Papadopoulos J, Bealer K, Madden TL. 2009. BLAST+: architecture and applications. BMC Bioinformatics 10:421. https://doi.org/10.1186/1471-2105-10-421.

92. Katoh K, Standley DM. 2013. MAFFT multiple sequence alignment software version 7: improvements in performance and usability. Mol Biol Evol 30:772-780. https://doi.org/10.1093/molbev/mst010.
93. Steenwyk JL, Shen X-X, Lind AL, Goldman GH, Rokas A. 2019. A robust phylogenomic time tree for biotechnologically and medically important fungi in the genera Aspergillus and Penicillium. mBio 10:e00925-19. https://doi.org/10.1128/mBio.00925-19.

94. Minh BQ, Schmidt HA, Chernomor O, Schrempf D, Woodhams MD, von Haeseler A, Lanfear R. 2020. IQ-TREE 2: new models and efficient methods for phylogenetic inference in the genomic era. Mol Biol Evol 37:1530-1534. https://doi.org/10.1093/molbev/msaa015.

95. Yang Z. 1994. Maximum likelihood phylogenetic estimation from DNA sequences with variable rates over sites: approximate methods. J Mol Evol 39:306-314. https://doi.org/10.1007/BF00160154.

96. Gu X, Fu YX, Li WH. 1995. Maximum likelihood estimation of the heterogeneity of substitution rate among nucleotide sites. Mol Biol Evol 12:546-557. https://doi.org/10.1093/oxfordjournals.molbev.a040235.

97. dos Santos RAC, Rivero-Menendez O, Steenwyk JL, Mead ME, Goldman $\mathrm{GH}$, Alastruey-Izquierdo A, Rokas A. 2020. Draft genome sequences of four Aspergillus section Fumigati clinical strains. Microbiol Resour Announc 9:e00856-20. https://doi.org/10.1128/MRA.00856-20.

98. Tamura K, Nei M. 1993. Estimation of the number of nucleotide substitutions in the control region of mitochondrial DNA in humans and chimpanzees. Mol Biol Evol https://doi.org/10.1093/oxfordjournals.molbev .a040023.

99. Hoang DT, Chernomor O, von Haeseler A, Minh BQ, Vinh LS. 2018. UFBoot2: improving the ultrafast bootstrap approximation. Mol Biol Evol 35:518-522. https://doi.org/10.1093/molbev/msx281.

100. Emms DM, Kelly S. 2019. OrthoFinder: phylogenetic orthology inference for comparative genomics. Genome Biol 20:238. https://doi.org/10 $.1186 / \mathrm{s} 13059-019-1832-\mathrm{y}$.

101. Buchfink B, Xie C, Huson DH. 2015. Fast and sensitive protein alignment using DIAMOND. Nat Methods 12:59-60. https://doi.org/10.1038/nmeth .3176 .

102. van Dongen S. 2000. Graph clustering by flow simulation: PhD thesis. University of Utrecht, Utrecht, the Netherlands.

103. Steenwyk JL, Buida TJ, Labella AL, Li Y, Shen X-X, Rokas A. 2021. PhyKIT: a broadly applicable UNIX shell toolkit for processing and analyzing phylogenomic data. Bioinformatics https://doi.org/10.1093/bioinformatics/ btab096.

104. Steenwyk JL, Buida TJ, Li Y, Shen X-X, Rokas A. 2020. ClipKIT: a multiple sequence alignment trimming software for accurate phylogenomic inference. PLoS Biol 18:e3001007. https://doi.org/10.1371/journal.pbio .3001007.

105. Vinet L, Zhedanov A. 2011. A 'missing' family of classical orthogonal polynomials. J Phys A: Math Theor 44:e085201. https://doi.org/10.1088/ 1751-8113/44/8/085201.

106. Waddell PJ, Steel M. 1997. General time-reversible distances with unequal rates across sites: mixing $\Gamma$ and inverse Gaussian distributions with invariant sites. Mol Phylogenet Evol 8:398-414. https://doi.org/10 $.1006 / \mathrm{mpev} .1997 .0452$

107. Tavaré S. 1986. Some probabilistic and statistical problems in the analysis of DNA sequences. Lect Math Life Sci 17:57-86.

108. Weber T, Blin K, Duddela S, Krug D, Kim HU, Bruccoleri R, Lee SY, Fischbach MA, Müller R, Wohlleben W, Breitling R, Takano E, Medema MH. 2015. antiSMASH 3.0-a comprehensive resource for the genome mining of biosynthetic gene clusters. Nucleic Acids Res 43:W237-W243. https://doi.org/10.1093/nar/gkv437.

109. Pluskal T, Castillo S, Villar-Briones A, Orešič M. 2010. MZmine 2: modular framework for processing, visualizing, and analyzing mass spectrometry-based molecular profile data. BMC Bioinformatics 11:395. https://doi .org/10.1186/1471-2105-11-395.

110. Caesar LK, Kvalheim OM, Cech NB. 2018. Hierarchical cluster analysis of technical replicates to identify interferents in untargeted mass spectrometry metabolomics. Anal Chim Acta 1021:69-77. https://doi.org/10 .1016/j.aca.2018.03.013.

111. Benjamini Y, Hochberg Y. 1995. Controlling the false discovery rate: a practical and powerful approach to multiple testing. J Royal Stat Soc 57:289-300. https://doi.org/10.1111/j.2517-6161.1995.tb02031.x.

112. Käfer E. 1977. Meiotic and mitotic recombination in Aspergillus and its chromosomal aberrations. Adv Genet 19:33-131. https://doi.org/10.1016/ S0065-2660(08)60245-x. 